\title{
LUZ, CUERPO, TRAUMA
}

\section{Antonio MÉNDEZ RUBIO}

Universitat de València

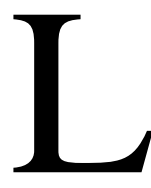

a palabra poética de Antonio Gamoneda, dada su condición extrañada, dañada e increíble, responde a lo que comúnmente se llama una voz interior. La expresión voz interior, como es sabido, se usa para nombrar una especie de palabra secreta, que nadie reconoce salvo quien no puede hacer otra cosa que oír su resonancia inesperada y peligrosa. Es de hecho la escucha de esa voz interior lo que vuelve a ese quien inesperado y peligroso de cara a los demás. Ahora bien, desde el desiderátum que busca en el lenguaje la deuda con los otros, «que la luz sea / un acto humano», desde esa concepción materialista de la escritura, la supuesta interioridad o abstracción solipsista de la voz se puede ver de otra forma: la voz interior puede estar siendo, en la práctica, solo una señal exterior a la supuesta voz exterior -cuando esta, a su vez, puede ser solo una voz más interior aún pero cuyo ensimismamiento está tan extendido por convención que se ha vuelto invisible. Valdría entonces la pena recordar que toda voz es ajena, está vinculada al peligro de la alteridad (y la alteración), a una enajenación tan áspera como dulce, liminar y más aún en tiempos de crisis social y de soledad común como son los nuestros.

Hay que insistir en que ese lugar es, menos que un destino o un horizonte, un punto de partida, un hic et nunc que se sabe irrenunciable. Y ese lugar es el lugar de la muerte. Escribía Hermann Broch en La muerte de Virgilio que la poesía es «la más extraña de todas las actividades humanas, la única que sirve para el conocimiento de la muerte» ${ }^{1}$. No en vano el propio Gamoneda había encabezado la sección «Frío de límites», del Libro del frío, con estas palabras de Broch: «símbolo que es realidad, realidad que se torna símbolo ante el rostro de la muerte». Lo que pasa, sin embargo, con la escritura de Gamoneda, como él mismo ha subrayado muchas veces, es que es una poesía escrita «desde la perspectiva de la muerte», esto es, que no es la muerte aquello de lo que en ella se habla, o por lo menos no es así ni siempre ni necesariamente, sino que la muerte es el lugar desde el que esta poesía se escribe, desde donde estos poemas pueden y deberían leerse. Hablar de la muerte es relativamente asequible, incluso por momentos reconfortante. Pero, ¿cuántas veces, a lo largo de toda una vida, seremos capaces de hablar desde la perspectiva de la muerte? ¿Hay algún otro sitio más lejos del miedo?

\footnotetext{
${ }^{1}$ H. Broch (1981), La muerte de Virgilio, 79.
} 
En toda la obra poética de Gamoneda, la muerte se despoja de sus velos trascendentes, de sus supuestas galas, para volverse cotidiana, común. Esto es así, a mi entender, en virtud del nexo que une la muerte y el cuerpo. El lugar de la muerte es el lugar del cuerpo. Y a la inversa. La muerte es muerte porque pertenece al cuerpo. El cuerpo es cuerpo porque pertenece a la muerte. El cuerpo se concibe como intensidad vulnerable, como herida que aún supura contra las agresiones de la historia, contra el olvido, con el olvido, contra el dolor, con el dolor, contra la pobreza, con la pobreza. Del cuerpo dañado en Gamoneda se desprende el valor político que en su poética tiene «esta latencia del cuerpo social» ${ }^{2}$. Y de aquí podría desprenderse, en fin, la relación que esta poética tiene con la experiencia del trauma. Así plantea la cuestión la especialista Judith Herman en su estudio Trauma y recuperación: «Los acontecimientos traumáticos violan la autonomía de la persona al nivel de la integridad corporal básica. El cuerpo ha sido invadido, dañado, profanado» ${ }^{3}$. Y a continuación cita Herman este testimonio de Tim O’Brien, excombatiente y superviviente del horror bélico: «Para el soldado normal la guerra produce la sensación -tiene la textura espiritual- de una enorme y fantasmagórica niebla, espesa y permanente. No hay claridad. Todo es un torbellino. (...) Los vapores penetran en ti». ¿No es elocuente la cercanía entre estas frases y la ambientación escenográfica de la poesía de Gamoneda, entendida como una huella de la guerra social, de un cuerpo vulnerado, de una luz para la que, contra todo pronóstico, «no hay claridad» ni puede haberla? ¿No es cierto que no puede entenderse del todo el temblor de esta escritura sin atender al temblor de ese pulso ya no otro, ya no ajeno, ya no exterior, del cuerpo, del cuerpo personal, del cuerpo impersonal, del cuerpo colectivo? ¿Y no puede adentrarse la lectura en esa comprensión por medio a su vez de la comprensión (psicológica, poética, política) del trauma?

Otro testimonio traumático lo recoge Mintz en Los anarquistas de Casas Viejas (2006). El 18 de enero de 1933 se iniciaron levantamientos libertarios en Barcelona, Madrid y Valencia. La insurrección popular fue sofocada, pero tres días después estalló inesperadamente la lucha en el pequeño pueblo andaluz de Casas Viejas. Trabajadores y campesinos, espoleados por el hambre de sus hijos y la miseria diaria, desfilaron por las calles del pueblo y proclamaron la llegada del comunismo libertario. En un intercambio de disparos en el cuartel de la Guardia Civil, dos guardias fueron mortalmente heridos. Llegaron refuerzos militares para detener la revuelta, pero fueron frustrados por una dura resistencia en la choza de un carbonero apodado Seisdedos. Siguiendo órdenes, los guardias incendiaron la choza matando a ocho campesinos. A continuación ejecutaron una terrible venganza fusilando a otros doce hombres.

En efecto, ¿cuántos ejemplos de esta naturaleza podrían traerse a colación aquí? Pero hay algo, con todo, que hace singular este acontecimiento minúsculo, esta resistencia imposible. Y es el registro funcionarial del testimonio dado por Dolores Benítez, vecina de Casas Viejas, tras ir en busca de sus dos hijos:

\footnotetext{
${ }^{2}$ F. Gómez-Porro (2007), «El cantor de las heridas», A. Gamoneda, Cecilia y otros poemas, 106.

${ }^{3}$ J. Herman (2004), Trauma y recuperación (Cómo superar las consecuencias de la violencia), 93.
} 


\begin{abstract}
[Dice] que sintió mucha gente gritar, y entonces se fue a la choza del Seisdedos y se los encontró "cadáveres cruzaítos uno con otro, la pierna del mayor encima de la del más chico". "Que había un reguero de sangre diforme, que no había dónde poner los pies". Que se fijó en que uno "tenía volaíta la cabeza, y en el otro ya no lo vio, porque al dolor se le perdió el mundo de vista"4.
\end{abstract}

Por si alguien tenía todavía alguna duda: por efecto del dolor, del grito en los límites, el arraigo en el mundo no se expresa solo mediante una imagen sino por la inminencia mortal de que ese mundo se pierda de vista.

Pero quizá haya que recalcar una vez más, en fin, que nada de esto cobraría la fuerza que cobra en la poética de Gamoneda si no fuera por una verdad elemental, humilde: el lugar del cuerpo, como el lugar de la muerte, es un lugar común. El lugar de lo común es el lugar del daño. Omnia sunt communia, gritaban las revueltas de los humildes en la baja Edad Media. Todas las cosas son comunes. Y también en esta poesía está ese rastro agonizante de los invisibles, la luz de nadie, esa causa de amor pendiente, «aquel olvido lleno de sangre». Y está ese pulso de revuelta, de subversión por el dolor, por la pobreza. Ya se apuntaba en Sublevación inmóvil (1960): «Mas la miseria tiene / una fuerza: el dolor». Y ya se recalca en 1977: «En este país, en este tiempo...» (...) «cuanto ha sucedido no es más que destrucción». Versos como estos (o como estos de Lápidas: «de tanta muerte como has muerto, España...»), que resuenan contra el fondo de una celebrada transición democrática, eufórica y normalizadora, quizá podrían ayudarnos a tomar precauciones contra cualquier esbozo, ya sea o no asumido, de estatalización de la escritura de Gamoneda.

Después de todas las destrucciones, de todas las separaciones, y todavía en su interior, va a quedar no obstante a la intemperie, imborrado, el murmullo oscuro y dulce de la desaparición, de las pérdidas. Con razón dice Miguel Casado que la reivindicación política es en esta escritura «apenas formulable» ${ }^{5}$, pues, asimismo, esa voz (que dice $e s o$ ) es apenas visible, apenas audible, por mucho que los altavoces la amplifiquen. Pero eso no significa que la reivindicación política no se dé, sino más bien que se da en condiciones de insuficiencia, de imposibilidad. Por lo demás, en ese núcleo poético crecen las elipsis, de modo que esta poesía hace con los acontecimientos históricos lo mismo que la realidad, pero a la inversa: los reconoce desaparecidos, pero para contemplarlos entonces en todo el frío de su espectralidad. No es extraño que la tradición realista más segura de sí misma no se haya sentido segura al confrontarse con esta mirada demasiado embelesada, demasiado inquietante.

\title{
Referencias bibliofráficas
}

BROCH, Hermann, La muerte de Virgilio, Madrid, Alianza, 1981.

CASAdo, Miguel, «Epílogo. El curso de la edad», A. Gamoneda, Esta luz (Poesía reunida (19472004), Barcelona, Galaxia Gutenberg-Círculo de Lectores, 2004.

GómEZ-Porro, Francisco, «El cantor de las heridas», A. Gamoneda, Cecilia y otros poemas. Madrid, Fondo de Cultura Económica-Universidad de Alcalá, 2007.

\footnotetext{
${ }^{4}$ Citado en J. R. Mintz (2006), Los anarquistas de Casas Viejas, 316.

${ }^{5}$ M. Casado (2004), «Epílogo. El curso de la edad», A. Gamoneda, Esta luz (Poesía reunida (1947-2004), 592.
} 
116 Tropelías. Revista de Teoría de la Literatura y Literatura Comparada, 21 (2014) Antonio Méndez Rubio

HERMAn, Judith, Trauma y recuperación (Cómo superar las consecuencias de la violencia), Madrid, Espasa-Calpe, 2004.

MinTz, Jerome R., Los anarquistas de Casas Viejas, Granada, Diputación de Cádiz-Diputación de Granada-Ayuntamiento de Benalup-Casas Viejas, 2006. 